\title{
THERAPEUTIC INTERVENTIONS EMPLOYED WHEN WORKING WITH MALTREATED CHILDREN
}

\author{
KRISTINA SESAR ${ }^{1}$, ARTA DODAJ ${ }^{\mathbf{2}}$ \\ ${ }^{1}$ University of Mostar, Faculty of Humanities and Social Sciences, Matice hrvatske bb, Mostar, Bosnia and Herzegovina, \\ ${ }^{2}$ University of Zadar, Ulica Mihovila Pavlinovića 1, Zadar, Croatia \\ contact: kristina.sesar@ff.sum.ba
}

Received: 27.09.2020.

Review article Accepted: 22.09.2021.

UDK: $615.851: 364.63-053.2$ 159.913:364.63-053.2 doi: $10.31299 /$ hrri.57.2.7

\begin{abstract}
A number of effective treatments are available for children and young people who have developed various forms of psychological difficulties as a consequence of traumatic experiences. The aim of this paper is to review the therapeutic approaches employed when working with children who have been exposed to various forms of abuse and neglect during their childhood. This paper provides relevant information to psychotherapists and counsellors on new trends in therapy, as well as techniques and possibilities in interventions in this field, not only with respect to traumatised children, but also family members and other caregivers involved in the child's life. Furthermore, this paper reviews the therapeutic interventions used to treat emotionally, sexually, and physically abused children, neglected children, children who have witnessed domestic violence, and children who have been exposed to multiple forms of abuse.
\end{abstract}

Keywords: child maltreatment, trauma, psychotherapy, child abuse, neglect, ecological-transactional model of development

\section{INTRODUCTION}

Newborn infants are completely dependent on their parents to satisfy their physiological and psychological needs. Under optimal conditions, parents relieve the stress faced by newborn infants by serving as regulators of physiology and behavior (Hofer, 2006). As they grow, children develop their own regulatory capacities during the first years of their life with the help of parents who serve as regulators. In early childhood, children are able to regulate their behavior, emotions, and physiology. However, for some children, parents cannot effectively fulfill their role as a buffer and co-regulator. When children have parents who cannot meet these two roles, they are vulnerable to the challenges in their environment. Although children can effectively cope with mild or moderately stressful events when they have parental/caregiver support, events that exceed their coping capacities often result inshort- and long-term negative outcomes (IOM and NRC, 2014). Children who have experienced abuse in early childhood face an increased risk of a number of short-term developmental, health, and psychological consequences (Cicchetti, Hetzel, Rogosch, Handley and Toth, 2016; Heim et al. 2009; Mersky and Reynolds 2007; Nemeroff, 2004). In adulthood, they continue to have an increased risk of developing mental illness, health difficulties, and lower socioeconomic status (Dodaj and Sesar, 2020).

Previous studies (Belsky, 1993; Cicchetti and Toth, 1998) have attempted to conceptualise the relative contribution of risk and protective factors associated with child development, especially with respect to childhood abuse, using transactional-bioecological or ecological models. Different versions of these approaches consider the development of the child in the context of the wider social environment. The first context for a child is family. Furthermore, children and families are part of a social system that includes the community, neighbourhood, and culture. The assumption underlying these models is that behaviour is complex and development is determined in many ways, includ- 
ing the characteristics of the children, parents, and families, as well as the neighbourhood/community and their interactions (IOM and NRC, 2014).

The ecological-transactional model, which was developed based on the ecological model of Belsky (1993) and the transactional model of Cicchetti and Rizley (1981), can be used to explain the contribution of contextual factors in the development of the consequences of exposure to childhood abuse and neglect: this model is especially beneficial due to its multiple etiological frameworks (Cicchetti and Lynch, 1993; Lynch and Cicchetti, 1998). Based on Cicchetti and Lynch's (1993) ecological-transactional theory, different qualities of a child's environments, such as their cultural environments, social resources, family characteristics, and individual differences, integrate to shape the way children respond to their surroundings/ world. They proposed that the characteristics of these environmental systems influence the way children negotiate different developmental tasks, as well as provide foundations of structures that can influence further development. These environmental systems were considered to have "potentiating factors" that could increase the likelihood of maltreatment or negatively affect the child, and "compensatory factors," that reduce the likelihood of maltreatment and violence, and their accompanying negative effects.

\section{TRAUMA ASSOCIATED WITH CHILDHOOD MALTREATMENT}

Traumatic events disrupt the typical feeling of control that individuals have over their lives, the feeling of connection with others, and the meaning they give to the world around them (Herman, 1992). Since these events are difficult experiences, a cognitive assessment of such events tends to determine the strength and intensity of the reaction and the duration of recovery, rather than the occurrence or absence of the psychological condition known as trauma (Arambašić, 2000). Trauma is defined as a state of emotional shock that creates significant and lasting harm on the mental health of a child, as well as their physical and/or emotional development.

Trauma may be linked to a specific incident, or may be continuous, lasting for many months or years (Courtois and Ford, 2009). Furthermore, existing classifications of traumatic events in childhood and adolescence distinguish traumatic events that do not involve abuse and neglect in the family from those that do (Profaca and Arambašić, 2009). Profaca and Arambašić (2009) state that traumatic events of abuse in the family have a cumulative effect, while other traumatic events can be classified as "experienced" or "not experienced". However, they emphasize that the culmination of different effects is also possible in the case of other traumatic events.

There are different types of traumatic experiences of abuse and neglect in childhood and adolescence: these experiences are by nature either directed toward a child or arise from the lack or omission of appropriate treatment and care for the child (Briere, 2002). Briere (1992) lists the following forms of abuse and neglect: sexual, physical, and psychological abuse, emotional neglect, and parental abuse of addictive substances. A child may be exposed to one form or various combinations of abuse at the same time or over a long period (Damashek and Chaffin, 2012; Sesar, Šimić and Barišić, 2010; Sesar, Živčić Bećirević and Sesar, 2008). Therefore, the term "complex trauma" was introduced in the field of traumatic psychology. Complex traumatic exposure refers to the child's experience of multiple traumatic events within the caregiver's circle (i.e.,) in the social environment that is assumed to be a source of security and stability in the child's life. Also, this term encompasses both short- and long-term consequences of exposure to multiple traumatic events (Cook, Blaustein, Spinazzola and van der Kolk, 2003). Furthermore, childhood maltreatment may be accompanied by other stressors, such as the consumption of psychoactive substances by the parents, domestic violence, mental illness of one or both parents, and loss of a parent (Damashek and Chaffin, 2012).

\section{EFFECTS OF TRAUMATIC EXPERIENCES ON CHILDREN AND ADOLESCENTS}

Trauma destroys the social systems of care, protection, and meaning that support human life. The reconstruction of these systems is a critical step in the recovery process. Disempowerment and disconnection from others are the essential 
features of psychological trauma (Herman, 2002). The consequences of trauma may differ from child to child (Lieberman and Knorr, 2007) and may be in a range from mild and short-lived symptoms to long-term and exhausting symptoms (Kanel, 2015; Zindler, Hogan and Graham, 2010). The severity of symptoms increases linearly with an increase in the number of forms of abuse to which the child has been exposed (Cecil, Viding, Fearson, Glaser and McCrory, 2017). The multiple stressors to which a child is exposed through different forms of abuse and neglect accumulate in different ways, and as a result, the consequences are more serious and less reversible (Briggs-Gowan, Carter and Ford, 2012; De Bellis, Woolley and Hooper, 2013; Lauterbach and Armour, 2016; Teicher, Anderson and Polcari, 2012). The consequences of traumatic experiences can be comprehensive, and have been observed in association with social, emotional, cognitive, behavioural, and academic functioning (Dodaj, Krajina, Sesar and Šimić, 2017; Profaca and Arambašić, 2009; Sesar et al., 2008; Sesar et al., 2010). Pynoos, Steinberg and Wraith (1995) list several areas of child development affected by traumatic exposure, including attentiveness, the ability to know and learn, self-image, perception of one's own effectiveness, development of competencies, moral development, awareness and experience of continuity, representation of self and others, specific worries, activation of the autonomic nervous system, impulse control, biological maturation, as well as interpersonal and maternal-fetal relationship. Psychopathology associated with traumatic experiences can develop in each of these areas.

\section{EFFECTS OF TRAUMATIC EXPERIENCES BASED ON THE ECOLOGICAL-TRANSACTIONAL THEORY}

The ecological-transactional theory (Cicchetti and Lynch, 1993) suggests that the younger a child is when he or she experiences an adverse event such as maltreatment - the more far-reaching its effects would be, since the same systems affected by the stress of maltreatment are in the process of development during the early years of life. Furthermore, the quality of the parent-child rela- tionship, which includes both the child's attachment strategy and parenting quality, has been shown to play an important role in determining the effect of a child's early experience of maltreatment on the later development of associated psychopathologies (Urquiza and Timmer, 2014). There is clear evidence that certain individual factors mediate the effects of trauma on the mental health of older children (Heim et al. 2009). These include early maltreatment (Cicchetti, Rogosch, Howe and Toth, 2010), early attachment relationships, social support, attributional styles, self-esteem, developing cognition about self and others, and social competence (Cicchetti and Valentino 2006). Experience of maltreatment can also be connected to differences in cognition and perception. Specifically, maltreatment is associated with differences in perception of emotion in others, the perception of the cause of emotional states (Perlman, Kalish and Pollak, 2008), and perception of internal vs. external control over events (Bolger and Patterson 2001). Furthermore, maltreatment is associated with the rationale that the child tells themselves about their role in the traumatic events and the way in which they process social information (Deblinger and Runyon, 2005). The findings of this particular study suggested that cognition begins to play a significant role in the mental health of adolescents, in a way that does not exist among younger children. It is thought that some of these early negative effects may have long-lasting consequences for children. A possible explanation is that these experiences make children more sensitive to later stressors because the early experience occurred at a sensitive period of development (Knudsen, 2004), when many changes occur at many levels of development. As a result, early maltreatment might have a particularly strong effect on different aspects of the child's development. Alternately, early maltreatment could be particularly devastating for children because there may be critical periods where certain positive experiences are necessary for optimal, healthy development to occur (Knudsen, 2004). Therefore, when children experience maltreatment at this stage, their developmental trajectories are irrevocably altered. There is no doubt that when maltreatment occurs early, it increases the likelihood of the child being exposed to further risk (Appleyard, Egeland, van Dulmen 
and Sroufe, 2005), which naturally increases the likelihood of long-term negative outcomes for these children.

\section{MAIN GOALS IN THE ASSESSMENT AND TREATMENT OF TRAUMATIZED CHILDREN AND ADOLESCENTS}

Before beginning to treat a child, it is important to assess the intensity and severity of abuse, the form and severity of dissociation, the child's perception of the events, and the feelings the child has towards the perpetrator of the abuse and other significant individuals in their life. A multidisciplinary approach is important during an assessment of abuse. It provides support to the child and the family, and a comprehensive assessment of the child's risk level, child protection, and family functioning (Buljan Flander and Profaca, 2010). The emphasis is on the assessment of all aspects of the child's development, psychosocial functioning, and post-traumatic symptoms. In addition to the nature of the event, the assessment of effects on the child and their subsequent treatment must take several other risk factors into account, such as the child's individual characteristics, family reactions to the event and psychopathological deviations in the family, guilt in the child, concern for the safety of family members or other close individuals, previous experiences of trauma and loss, and closeness to the victim (in situations of witnessing the event) (Pynoos and Nader, 1990). A well-conducted multidisciplinary assessment of a traumatised child allows for a better definition of the need for eventual intervention. Based on the assessment, treatment is planned for the child and family by involving and cooperating with different parts of the system, to help the child recover from the trauma of abuse (Buljan Flander and Profaca, 2010; Profaca, 2016). When planning the treatment protocol for a traumatised child, it is very important to choose therapeutic techniques that are appropriate for the child's age, the family dynamics, and the individual needs of the child (Damashek and Chaffin, 2012; Trocmé, Fallon, Sinha, Wert, Kozlowski and MacLaurin, 2013). Interventions differ if the child has experienced one or more traumatic events, as well as if they have been exposed to trauma in the family and/ or outside the family. Some of the traumatic events may require procedures to prevent the development of posttraumatic symptoms, while in the case of others, intervention procedures related to psychosocial functioning should be provided to reduce the risk of posttraumatic symptoms (Profaca, 2016). According to Herman (2002), the recovery process can be conceptualised into three stages: establishing safety, retelling the story of the traumatic event, and reconnecting with others. The recovery process is based on empowerment of the survivor and restoration of relationships. Treatment must be appropriate to the victim's stage of recovery (Herman, 2002). In order to avoid possible projective identification processes, the therapist is expected to be able to cope with the child's experience, their suffering, and the feelings they have towards the perpetrator (Lev-Wiesel, 2015). Therapeutic approaches include working with the child, the parents and other family members, and the social community (Scott, 2014). Therapists require a strong professional support system to manage the psychological consequences of working with traumatised children (Herman, 2002). What is extremely important is a multi-disciplinary approach, including paediatricians, psychologists, a child psychiatrist, social workers, and other experts.

\section{REVIEW OF THERAPEUTIC INTERVENTIONS EMPLOYED WHEN WORKING WITH MALTREATED CHILDREN}

Several approaches have been developed for the early intervention and therapeutic treatment of maltreated children. Numerous empirical studies have been conducted to examine the efficacy of specific treatments for traumatised children. Some of the recommendation interventions include psycho-education, crisis interventions, short- and longterm abuse-oriented treatments, and more complex interventions (Tavkar, Poonam and Hansen, 2011). The aim of this paper is to provide a review of the most effective therapeutic approaches used in the treatment of children exposed to various forms of trauma as a consequence of abuse and neglect during childhood. Each approach presented in this paper has its own specific features. We will present interventions focused on the child, those aimed at the parents, and approaches aimed at both the child 
and the parents at the same time. It is inevitable that different approaches will overlap, and that it is difficult to consider them separately, especially given that abuse and neglect often take place in the family context. However, in order to simplify the presentation and emphasise on specific features of individual treatments, we will present each therapeutic approach separately.

\section{METHODS}

We systematically reviewed studies examining treatments for child abuse and neglect following the principles outline in the Preferred Reporting Items for Systematic Reviews and Meta-Analyses (Moher, Liberati, Tetzlaff and Altman, 2009). We conducted a detailed review of relevant literature published within the last 30 years $(1984-2018)$ that was archived in electronic databases, including EBSCOHost, ERIC, ResearchGate, SCOPUS, and Web of Science. No language restrictions were applied. The search criteria included any combination of terms indicative of psychological treatment and child abuse/maltreatment in the title, abstract, and keywords. We included studies that reported the effects of individual and group treatment, including an ecological framework. We identified and analysed a total of seventy studies found in the searched databases.

\section{INDIVIDUAL PSYCHOTHERAPY}

Treatments aimed at traumatised children focus on removing the immediate/current consequences of exposure to experiences of abuse and creating a supportive form of psychological functioning in the child in the long-term.

Trauma-Focused Cognitive Behavioural Therapy (TF-CBT) specifically focuses on children and adolescents exposed to sexual abuse, and is one of the most frequently researched therapeutic interventions for children who are victims of sexual abuse. However, TF-CBT has also been used as the therapy of choice in work connected with a wide range of traumatic events in children, including emotional abuse (Cohen, Mannarino, Kliethermes and Murray, 2012).

TF-CBT is a hybrid treatment model incorporating cognitive behavioural, interpersonal, and family therapy principles with trauma-sensitive interventions for children and parents exposed to traumatic events. It is designed to combine both fidelity to the model (i.e., offering a general structure through specified child and parent treatment components that are generally provided in the same order), while encouraging a significant degree of therapist flexibility in adapting the model to that specific child, family, and community (Cohen, Mannarino and Deblinger, 2006a).

The primary goal of TF-CBT is to reduce symptoms of posttraumatic stress disorder (PTSD) among children and adolescents. It provides a structure for the use of cognitive-behavioural principles in the context of two important developmental considerations: the role of the caregiver, and the developing nature of emotion regulation and coping capabilities of the child. The model was originally designed to address PTSD symptoms associated with sexual abuse, such as depressive symptoms, behaviour problems, and unhelpful thoughts and feelings regarding the abuse. In the past decade, the model has been further developed to treat children exposed to various types of abuse and other traumatic experiences (e.g., physical or emotional abuse or neglect, and witnessing community or domestic violence, traumatic loss, war, or natural disasters). TF-CBT is structured in 12-16 sessions of outpatient intervention depending on the needs and abilities of the traumatised child and caregivers. The model also addresses the emotional reactions of non-abusive parents and caregivers (individuals who were not involved in perpetrating the abuse, but had experienced PTSD symptoms related to the abuse). Depending on the needs of the child, parents and caregivers who may have committed domestic violence or physical abuse, but who have subsequently received successful treatment or otherwise observed to be supportive of the child and able to ensure physical and emotional safety, may also be involved in treatment. There are five core elements of the current TF-CBT model and the iterations that preceded it including, psycho-education; coping strategies, such as relaxation, identification of feelings, and cognitive coping; gradual exposure, for example, through imagining or in-vivo exposure; cognitive processing; and caregiver participation, such as parent training and joint sessions (de Arellno et al, 2014; Cohen et al., 2006a). 
Research into the effectiveness of TF-CBT, on its own or in combination with other interventions such as play therapy and behaviour management strategies (Allen and Johnson, 2012; Bol, 2008; Cohen, Berliner and Mannarino, 2010; Feather and Ronan, 2009; Grasso, Joselow, Marquez and Webb, 2011; Saywitz, Mannarino, Berliner and Cohen, 2000; Scheeringa, Weems, Cohen, Amaya-Jackson and Guthrie, 2011) demonstrate the effectiveness of cognitive-behavioural approaches to mitigate posttraumatic stress reactions, treat emotional and behavioural difficulties related to experiences of abuse, improve coping skills, develop of a sense of security in the child, and improve emotional processing.

The psychoanalytical approach to treatment, specifically for children exposed to sexual abuse, aims to reduce the symptoms of PTSD, develop awareness of subconscious defence mechanisms, and improve adjustment (Trowell et al., 2002). Alongside psychoanalytical sessions, the therapist also works with the parents so they can be supportive during treatment, and helps the parents to resolve problems within the family. Trowell et al. (2002) compared the effectiveness of individual and group therapy in terms of reducing the symptoms and improving the functioning of victims of abuse, and found that although both groups of subjects showed fewer psychopathological symptoms and improved general functioning, individual treatments were more effective in mitigating the symptoms of PTSD.

Chorpita and Weisz (2009) propose a Modular Approach to Children with Anxiety, Depression, Trauma and Conduct (MATCH-ADTC), which is an evidence-based treatment for children between the ages of six to 15 years. In contrast to most treatment approaches aimed at one form of psychological difficulty, MATCH-ADTC is designed to treat anxiety, depression, PTSD, as well as behavioural problems. Components of this treatment very often include CBT protocols for treatment of these psychological difficulties. The treatment is flexible and organized sequentially so that it can be adjusted to the needs of each child. Chorpita et al. (2017) demonstrated that this modular approach is much more effective than individual attempts by a therapist to integrate various forms of treatment in order to meet the complex needs of a child affected by multiple experiences of abuse and neglect.

The results of extensive research have also proven the effectiveness of Eye Movement Desensitization and Reprocessing (EMDR) in the treatment of trauma related to PTSD caused by war experiences, criminal acts, sexual and domestic violence, as well as in the treatment of trauma occurring on a smaller scale (Shapiro, 2014). EMDR therapy is an eight-phase treatment approach composed of standardized protocols and procedures. The eight phases and three-pronged protocol facilitate a comprehensive evaluation of the clinical picture, client preparation, and processing of the following: a) past events that set the foundation for pathology, b) current disturbing situations, and c) future challenges (Shapiro, 2012; 2014). Another study indicated that EMDR therapy can be more successful than CBT for the treatment of sexually abused girls (aged 12 to 13 years) (Jaberghaderi, Greenwald, Rubin, Zand and Dolatabadi, 2004). EMDR has been successfully used for the rapid desensitization of traumatic memories and cognitive restructuring that leads to a significant reduction in the symptoms of emotional stress, distracting thoughts, anxiety, repeated memories of the event, and nightmares. EMDR takes into account all aspects of the traumatic and stressful experience, including neurophysiological, cognitive, emotional, and behavioural features. The movement of eyes and other forms of alternate left/right stimulation, for instance, alternate tapping with the left and right hands, or audio signals in the left and then the right ear, can be analysed along with images of a scene from the traumatic event and the negative convictions, the emotional suffering, and the physical sensations related to it: EMDR can assist the processing of such information right up to its final resolution. In the final phase of treatment, the traumatic experience is used in a constructive manner, and integrated into the individual's positive cognitive-emotional network in order to find a suitable solution (Shapiro, Kaslow and Maxfield, 2007).

Interventions based on play therapy are often used to reduce internalisation and externalisation behaviours, as well as behaviours connected with trauma (Stubenhort, Cohen and Trybalski, 2010). 
Research has been conducted to verify the efficacy of this approach. For example, Scott, Burlingame, Starling, Porter and Lilly (2003) found that play therapy has a positive effect on the child's self-respect and improves their general mood and social interaction skills. In combination with other therapeutic approaches, it can also be effective in improving coping skills and family functioning.

Misurell, Springer, Acosta, Liotta and Kranzler (2014) used CBT based on play to focus on internalised and externalised behaviours, symptoms specific to trauma, and sexually inappropriate behaviour. It was shown that this approach was effective in reducing behavioural problems for all age groups, as long as it is integrated into play therapy.

\section{GROUP PSYCHOTHERAPY INTERVENTIONS}

Group psychotherapy interventions are effective treatment interventions for children and youth exposed to childhood maltreatment (Foy and Eriksson, 2001; Heiman and Ettin, 2001; Wanlass, Moremo and Thomson, 2006). Group psychotherapy provides individuals with a unique opportunity for self and interpersonal learning. Furthermore, it allows members to address the effects of interpersonal victimisation (Briere and Elliott, 1997). Group therapy offers the opportunity to receive understanding and support from others who have had similar experiences, as well as to give support to others (Foy et al., 2001). Individuals in group therapy can achieve normalisation of shame, isolation, helplessness, powerlessness, and betrayal (Heiman and Ettin, 2001). Additionally, group interventions may be structured to focus on maximising skills associated with resiliency, leading to improved treatment outcomes for traumatised children (Wanlass et al., 2006). Group treatment intervention for traumatised children covers a wide area of theoretical models, ranging from the oldest psychodynamic ones to more recent cognitive-behavioural approaches (Lomonaco, Scheidlinger, and Aronson, 2000).

Cognitive behavioural group treatment programs are designed to address the multiple sequelae common to physically abused school-aged chil- dren (i.e., emotional, behavioural, and cognitive symptoms related to traumatic experiences). Group treatment includes psycho-education, group cohesion, coping skills, and emotional, behavioural, and cognitive regulation. According to de Arellano et al. (2014), CBT group treatment programs led to a decrease in self-reported measures of trauma-related emotional symptoms in children who had previously participated in this kind of group treatment.

The multidimensional model of group therapy described by Lindon and Nourse (1994) is recommended as the treatment of choice when working with sexually abused adolescents. A group is an environment where victims of sexual abuse can meet and communicate with other individuals who are facing the same difficulties. This form of therapeutic intervention with children and adolescents exposed to sexual abuse contains three basic concepts: skills training, psychotherapeutic interventions, such as "the empty chair", and an educational component that focuses on providing further information about the sexual anatomy of men and women. The advantages of group therapy over individual therapy are the empowerment of individuals and improvement of their psychological state, the development of confidence in a supportive environment, provision of support, the development of a feeling of community, mitigation of the feeling of shame that occurs as a result of the experience of sexual abuse, and easing the symptoms of depression and anxiety (Westbury and Tutty, 1999; Yalom and Leszcz, 2005). Lindon and Nourse (1994) also stated that evaluation of this form of treatment, based on self-assessment, indicates its effectiveness, especially in girls where it resulted in an increase in their positive self-image.

Cognitive-Behavioural Intervention for Trauma in Schools (CBITS) is a school-based group and individual intervention program that is aimed at multicultural populations (Jaycox, 2004). This therapeutic approach was originally designed to address symptoms of PTSD, general anxiety, and depression among children exposed to multiple forms of trauma (community and school violence, accidents and injuries, physical and sexual abuse, domestic violence, and natural and man-made disasters). CBITS is a 10 -week treatment program conducted in small groups with 5-8 children. In 
addition, the CBITS program includes three individual sessions, including two parent informational sessions and a teacher education session. The CBITS program has three main goals: to reduce symptoms related to trauma, to build resilience, and to increase peer and parent support through cognitive behavioural techniques. The first phase of the program includes an introduction, group procedures, description of the treatment program, and reasons to participate. In the next few sessions, participants are educated about common reactions to stress, relaxation techniques, linking of thoughts and feelings, and combating negative thoughts. After that, they are introduced to avoidance and coping mechanisms, construction of a fear hierarchy, and cognitive coping strategies. The final steps in the program include exposure through imagination/drawing/writing, introduction to social problem solving, practicing social problem solving, relapse prevention, and ultimately, a graduation ceremony. All skills are presented with a mixture of didactics, age-appropriate examples, and games to solidify concepts. Homework is given between sessions with an emphasis on applying techniques to each child's own difficulties (Cohen et al., 2006a). Evaluation studies confirm the efficiency of the CBITS program (Kataoka et al., 2011; Morsette et al., 2009).

Group treatment is considered an ideal modality for adolescent victims of child sexual abuse (CSA) since adolescents emphasise on peer relationships in their struggle for identity development (Avinger and Jones, 2007). The psychodrama model, described by Carbonell and PartelenoBerehmi (1999), focused on giving adolescent girls the opportunity to process the trauma through their senses using a dramatization re-enactment which each girl directed. In the warm-up phase, the girls had opportunities to bond, develop a group culture, and learn theatrical skills and core concepts. During the action phase, each girl had the opportunity to stage, direct, and act out what happened to her. During this re-enactment, the therapists had the opportunity to reframe the events of the trauma in more adaptive ways. Each client was also given the opportunity to create new, positive endings to her story, in the hope of restoring the clients' sense of personal control. Alternative for- mats were offered when a re-enactment seemed too overwhelming for the client. During the final phase of each session, the girls had the opportunity to share their experiences of the dramatization and any feelings it brought up for them. In the sharing phase, it was important for therapists to allow for emotional processing of material without becoming overly analytical about it (Avinger and Jones, 2007; Carbonell and Parteleno-Berehmi, 1999). Carbonell and Parteleno-Berehmi (1999) evaluated the effectiveness of psychodrama groups with traumatised middle-school girls and found a significant reduction in the proportion of self-reported difficulties among participants with withdrawn behaviour and anxiety/depression. Interviews conducted with the participants reinforced the value of psychodrama group participation in the resolution of trauma, as well as in increasing a sense of competency and self-efficacy. According to Avinger and Jones (2007), psychodrama therapy models resulted in a decrease in depressive symptoms in sexually abused girls.

The results of evaluation research also confirm the positive effects of the group therapy approach when working with children who have witnessed domestic violence (Cahn, 2006; Devaney, 2015). Although child neglect is a highly prevalent form of child maltreatment, limited rigorous treatment studies have been conducted in this area. This may be in part due to the difficulty in defining and measuring child neglect. In addition, it is difficult to access populations in which child neglect does not overlap with some other form of maltreatment, such as physical or sexual abuse (Black, 2000).

\section{PSYCHOTHERAPY FOCUSED ON PARENT-CHILD INTERACTIONS}

Despite extensive research showing that a family's characteristics are risk factors for emotional abuse, there is still an insufficient number of therapeutic approaches aimed at understanding parent-child interactions. Treatments aimed at the parent-child relationship are primarily focused on changing the negative interaction that exists between parents and their child, as well as improving parenting skills (Barlow and SchraderMacMillan, 2009). 
Parent-child interaction therapy is certainly one of the better-known therapeutic approaches aimed at improving the quality of interaction between parents and their child. It is recommended for the treatment of physical and emotional abuse of children and/or neglected children up to the age of 12 years (Royse, 2015). The treatment includes therapeutic work with the parents and the child. The parents are taught about the importance of praising their child, thinking about what the child says, mimicking the child's reactions and explaining their behaviour, and showing an interest in them. After that, the parents take part in playing with their child and demonstrate the use of the patterns of behaviour they have learned (McNeil and Hembree-Kigin, 2010). This approach helps parents and guardians to develop positive behaviours through intensive inclusion in work with children.

An additional approach that improves the quality of interaction between parents and their child is Combined Parent-Child Cognitive Behavioral Therapy (CPC-CBT). This approach was primarily developed for work with physically abused children, parents raising their children in an inappropriate and aggressive manner, and for children and parents where a significant conflict has been found in their interaction and communication. In addition to this, it can also be used in work with children who are witnesses of domestic violence and children who have experienced of sexual and physical abuse (Runyon, Deblinger and Schroeder, 2009). The approach includes elements of CBT used separately with the parents, with the child, as well as with the parents and child at the same time. It includes psychological education, training in parenting skills, planning family safety, and processing traumatic experiences (Runyon et al., 2009). Clinical practice and empirical results have so far shown the wide application and effectiveness of the cognitive behavioural approach in work with children and families with experience of abuse (Runyon et al., 2009).

Becker-Weidman (2006) described another approach called Dyadic Developmental Psychotherapy (DDP), which is aimed at developing a collaborative relationship between the therapist and the child, the parents and the child, and the therapist and the parents. DDP differs from traditional therapies because it places a greater emphasis on experience and the process rather than on verbalization and content. The aim of a DDP therapy session is to help the child develop their own personal experience related to the trauma, as well as to help the child in the process of reducing the consequences of the trauma by modelling a healthy style of attachment, reducing shame, nurturing physical contact, and teaching regulation of emotions. For the sake of comparison, traditional therapies focus on techniques to resolve problems and encourage the child to talk about what happened, their experiences, and teach them how to cope with thoughts and emotions related to what happened (Becker-Weidman, 2006).

Non-Directive Supportive Therapy (NST) is aimed at children and their parents in order to establish therapeutic confidence, which affirms, strengthens, and validates both the child and the parents (Cohen, Mannarino and Knudsen, 2005). The literature on this therapeutic approach is limited. However, research conducted on adults and children with depression has shown positive outcomes in both after using this therapeutic approach (Cohen et al., 2005).

Interventions aimed at attachment promote a healthier relationship between parents and their child, focusing on physical and emotional connection and communication. Using a case study, May (2005) examined the effectiveness of Family Attachment Narrative Therapy (FANT), a new form of family therapy that was developed for work with children exposed to abuse in early childhood. Gentle, calming, non-provocative, and unobtrusive narratives told by the parents provide an alternative, restorative experience for the child, with the aim of redirecting and changing the child's destructive internal working model. The outcome of this treatment is to improve functioning and the ability to accept a nurturing and caring relationship that offers love and security. According to Schofield, Lee and Merrick (2013), children and their parents/ guardians need to develop safe, stable, and nurturing relationships to mitigate the consequences of trauma caused by abuse in childhood. When working with parents, this therapeutic approach 
may also be applied to other caregivers in the child's environment, such as family members, teachers, or school staff.

Attachment Based Family Therapy (ABFT) is an empirically supported treatment designed to capitalise on the innate biological desire for meaningful and secure relationships (Diamond, Russon and Levy, 2016). The therapy is grounded in attachment theory, and provides an interpersonal, process-oriented, trauma-focused approach to treating adolescent depression, suicidality, and trauma. The therapist provides a secure base for the client to explore internal working models and develop trust in others during the individual therapy (Diamond, Diamond and Levy, 2013). The main goal in family therapy is to understand and improve family relationships through interactional and interpersonal work (Krauthamer Ewing, Levy, Boamah Wiafe, Kobak and Diamond, 2016). ABFT offers a clear structure and road map to help therapists quickly address attachment ruptures that lie at the core of family conflict. ABFT is organised around five treatment tasks: 1) The Relational Reframe; 2) Adolescent Alliance; 3) Parent Alliance; 4) Repairing Attachment; and 5) Promoting Autonomy. These tasks represent therapeutic challenges or processes that serve as the building blocks leading to treatment outcomes. Tasks are not the same as sessions; they may take several sessions to accomplish. The model therefore provides structure, but also enough flexibility, for therapists to address the idiosyncratic challenges that each family brings to treatment. The five tasks provide therapists with strategies and themes to help accomplish the goals of each task (Krauthamer Ewing et al., 2016). Several clinical trials and process studies have demonstrated empirical support for the model and its proposed mechanism of change (Diamond et al., 2016).

Treatments based on children and their family members mastering behaviour skills are the foundation of all contemporary therapies. These programs have proved to be consistently effective in ensuring personal hygiene and dental care, adequate nutrition for the child, hygiene and cleanliness in the family home, reducing danger in the family home, as well as improving the affective responses of the parent/guardian who has been neglecting the child (Donohue, Romero and Hill, 2006).

\section{PSYCHOTHERAPY FOCUSED ON PARENTS}

Approaches aimed at the family have been developed in order to improve positive and effective functioning in the family (Cohen, Mannarino, Murray and Igelman, 2006b). Within this approach, the commonly used programs are the Positive Parenting Program and the Family Preservation Program. The Positive Parenting Program is based on a cognitive-behavioural approach, and its aim is to increase parental competence, reduce the use of punishment as a method of disciplining the child, reduce behavioral problems in the child, improve communication between the parents, and reduce parental stress related to raising their child (Mazzucchelli and Sanders, 2010). Alongside working with the parents, the program may also include working with a child who has behavioral difficulties. So far, studies have demonstrated the effectiveness of the program by showing a reduction in dysfunctional parental forms of behaviour and behavioral problems in children, as well as an increase in parental competence (de Graff, Speetjens, Smit, de Wolff and Tavecchio, 2008; Sanders, MarkieDadds, Tully and Bor, 2000). However, in cases of parents who emotionally abuse their children, there is no evidence of the effectiveness of this treatment in the literature. In addition, the Family Preservation Program includes the use of various strategies aimed at reducing abuse and neglect by parents, reducing family conflicts, improving behavioural problems in the child, and teaching the family successful skills in the realisation of their relationships (Child Welfare Information Gateway, 2014). The results related to the effectiveness of this treatment in the literature are still ambiguous (Mather, Lager and Harris, 2007).

Multi-Systemic Therapy (MST) has found support in research (Corcoran, 2000; Swenson, Schaeffer, Henggeler, Faldowski, and Mayhew, 2010), and the positive outcomes of this approach are listed here: increased support, family cohesiveness and adaptability, and a reduction in anger and conflicts (Corcoran, 2000). MST is aimed at the 
aspects of parenthood related to abuse, reduction of physical abuse and neglect of the child in the family, and increasing support from the parents (Swenson et al., 2010).

Treatment procedures targetting parents/guardians, primarily mothers, can also be conducted in therapeutic communities or safe houses (Cahn, 2006; Devaney, 2015; McConnell, Barnard, Holdsworth and Taylor, 2014). In terms of parents/ guardians, the starting point is an examination of the parents' beliefs and attitudes about domestic violence, developing awareness of the harmful effects of domestic violence for the child, teaching successful parenting skills and successful parent-child interaction, and the protection and promotion of the mental health of the parent/guardian (Cahn, 2006). Most treatments include group work with partners, which is often characterised legally as mandatory psychosocial treatment, where cognitive, affective, and behavioural changes in the partner/parent/guardian are systematically monitored in order to develop successful instruments and measures to reduce violent behaviour (Cahn, 2006; McGinn, Taylor, McColgan and Lagdon, 2016; McMahon, Devaney and Lazenbatt, 2009). Therapy work aimed at parents/guardians (with a direct positive contribution to the parents/guardian) also indirectly achieves positive outcomes for the child (Bancroft and Silverman, 2002). Work with parents makes a significant contribution to reducing domestic violence (Cahn, 2006; Chanmugam and Teasley, 2014). However, the fact that this is a protective measure of mandatory psychosocial treatment gives rise to the danger that the partner/ parent may resist participation in this form of work.

\section{FAMILY INTERVENTIONS}

These systemic programs focus on improving parent-child interactions along with parental training. Different family treatments that have been evaluated for abused and neglected children include MST (Brunk, Henggeler and Whelan, 1987) and Multifamily Group Therapy (MFGT) (Meezen and O'Keefe, 1998).

MFGT includes elements of behaviour modification, CBT, and reality therapy (Cohen et al., 2006b). The underlying goal of MFGT is to use a group of 6-8 families to change the behaviour of individual family members and alter family interaction patterns. Among others, MFGT incorporates family systems, group therapy, psychoeducation, and behavioral management components (Cohen et al., 2006b). Compared to the families receiving traditional family therapy, those engaged in MFGT showed significantly more positive changes in family functioning, children reported more assertiveness and less submissiveness, and caregivers reported fewer behavioral problems, including aggressiveness (Cohen et al., 2006b; Meezen and O’Keefe, 1998).

Furthermore, Multisystemic Therapy for Child Abuse and Neglect (MST-CAN) is a treatment for adolescents between the ages of 10 to 17 years that is based on an ecological model. The therapy treatment is aimed at young people, parents, and their families in which the presence of physical abuse and neglect has been established. The treatment is aimed at reducing abuse, preventing removal of the child from the family, reducing (psychological and physical) aggression in the relationship between the child and the parent, and improving the mental health of parents and their parenting skills. The use of this therapeutic approach requires a specially educated team that needs to be available continuously (Bentovim, Gray and Pizzey, 2018). MST-CAN has proved to be an effective therapeutic approach in reducing removal of children from their homes, reducing abusive and neglectful behaviour by parents, mitigating psychological difficulties among parents and children, and increasing social support (Swenson and Schaeffer, 2018).

\section{PHARMACOLOGICAL INTERVENTIONS}

Many child psychiatrists use a pharmacological approach to treat traumatised children (Huemer, Erhart and Steiner, 2010). Medication is prescribed with the aim of treating the consequences and symptoms related to trauma caused by abuse. Psycho-pharmaceuticals with various psychoactive components can be used to treat symptoms of anxiety, depression, bipolar disorder, attention deficit hyperactivity disorder, and sleep disorders (Huemer et al., 2010). 


\section{DISCUSSION AND CONCLUSION}

This review summarises our current knowledge regarding therapeutic interventions for children who experience various forms of child abuse, as well as their family members. This is an area of research with a large amount of empirically tested interventions aimed at treating specific types of abuse. In terms of individual therapy, TF-CBT, the psychoanalytic approach, and EMDR have provided extensive empirical evidence for children who have experienced sexual abuse, and MATCH-ADTC treatment and play therapy demonstrate promise for reducing symptoms specific to traumatic events. In terms of group therapy, the multidimensional model of group therapy and psychodrama have been proven effective when working with sexually abused individuals, while CBT is effective for those who have been physically abused, and CBITS for those exposed to multiple forms of trauma and abuse. CBITS group work is effective when working with children exposed to multiple traumas, and also includes work with parents and teachers. This review shows that among the different therapeutic approaches based on the interaction between the parent and their child, CBP-CBT and parent-child interaction therapy are most useful in treating physical abuse. Other types of therapeutic interactions between the parent and the child are limited in their efficacy. A psychotherapeutic approach aimed at the parents through a program aiming to preserve the family and multi-system therapies are useful when working with parents who neglect their children. When it comes to choosing the appropriate psychotherapy treatment for children, some therapists may include pharmacological intervention as well to decrease symptoms related to trauma abuse.

With regards to treatment for the consequences of childhood abuse and neglect, we recommend the following topics for future research studies in this field: first, studies which examine the effectiveness of treatment approaches for specific types of abuse and neglect should also try to test their effectiveness for other types of abuse. This is especially important since the experience of multiple childhood abuse has more severe, long-term outcomes than a single type of abuse. Therefore, the needs of children exposed to multiple forms of abuse in childhood may be complex and challenging for the therapist. Bentovim et al. (2018) emphasized that in such cases it is necessary to develop a multi-focal approach aimed at the multiple forms of abuse and neglect and the consequences that abuse had on the functioning of children and young people. Further, measurement of abuse and neglect should be multidimensional and culturally adapted in order to obtain a broader understanding of the efficacy of these therapeutic approaches with respect to different aspects of trauma and subgroups of individuals. Based on this review, we conclude that CBITS has been the most effective approach for work in a multicultural environment. Hence, researchers should ensure that studies about therapeutic effectiveness are methodologically sound and comply with the needs and insights from clinical practice (Sackett, Straus, Richardson, Rosenberd and Hayns, 2000; Sinanan, 2015). In particular, there is a lack of well-designed research on the effectiveness of group psychotherapy and psychotherapy focused on parents and their interaction with children.

Second, it also seems necessary to evaluate the effectiveness of treatments specifically for psychological abuse, but also for those witnessing domestic violence and facing neglect. Although there is growing evidence from empirically supported treatment programs available for treating the effects of sexual and physical abuse, and some for multiple forms of abuse, there seems to be a inadequate amount of studies on effective therapies for other types of abuse. Considering that psychological abuse in childhood is a core component for all other types of abuse (Leeson and Nixon, 2011), it is important that we have a good understanding of effective programs that can address this type of abuse. It could provide us with an opportunity to identify components of programs that can enhance outcomes for other types of abuse.

Third, therapeutic interventions should be directed towards assessing their efficacy for a range of short- and long-term outcomes that children exposed to abuse experience. Most studies appear to report efficacy in reducing posttraumatic symptoms of abuse, as well as symptoms of depression, anxiety, and behavioural difficulties. There are a variety of other symptoms in children exposed to abuse, and researchers should examine 
the relevance of interventions for different types of problems. A detailed evaluation of therapeutic efficacy for a range of symptoms has been conducted for sexual abuse (see Hetzel-Riggin, Brausch and Montgomery, 2007). For other types of childhood abuse, this area of research is still in its infancy.

Finally, the effectiveness of these therapies must be verified in a clinical setting. Although verifying the effectiveness of treatment in a clinical setting is very challenging, it is only possible with mutual collaborations between researchers and clincians/ practitioners. This collaboration can also create an opportunity for mutual sharing of information and motivate practitioners to use evidence-based therapy studies.

In conclusion, the findings of this literature review suggest that various therapeutic approaches effectively reduce the symptoms experienced by maltreated children. When choosing the appropriate treatment for children, therapists must pay attention to a wide range of abusive and neglectful experiences, and their connection to the current psychological difficulties of their clients. The task of the professional is to recognise the client's needs, respect their cultural and other differences, assess specific characteristics, as well as recognise their strengths and weaknesses. Interventions must aim to empower the child, but also to mitigate their symptoms. These interventions must be formulated using evidence-based psychotherapy supported by scientific evidence and compatible to clinical needs (Sackett et al., 2000; Sinanan, 2015). If the treatment of abused and neglected children is approached in this way, it will not only be a form of treatment, but it will also represent a program to prevent the negative consequences of abuse and neglect in adulthood (Cook, Schnurr and Foa, 2004). Since there have been significant advances in understanding and treating trauma in childhood, counsellors and therapists should strive to gather sufficient information about new approaches. They should have the opportunity to educate themselves further when a new approach proves effective. In the same way, they should raise public awareness about traumatic experiences in childhood in the hope that this will increase the possibility for children to receive the treatment they need. 


\section{REFERENCES}

Allen, B., \& Johnson, J. C. (2012). Utilization and implementation of trauma-focused cognitive-behavioural therapy for the treatment of maltreated children. Child Maltreatment, 17, 80-85. https://doi.org/10.1177/1077559511418220

Appleyard, K., Egeland, B., van Dulmen, M. H., \& Sroufe, L. A. (2005). When more is not better: the role of cumulative risk in child behavior outcomes. Journal of Child Psychology and Psychiatry, and Allied Disciplines, 46(3), 235-245. https://doi.org/10.1111/j.1469-7610.2004.00351.x

Arambašić, L. (2000). Stresni i traumatski događaji i njihove posljedice. In L Arambašić (Eds.), Psihološke krizne intervencije (pp. 11-31). Zagreb: Društvo za psihološku pomoć.

Avinger, K. A., \& Jones, R. A. (2007). Group treatment of sexually abused adolescent girls: A review of outcome studies. American Journal of Family Therapy, 35(4), 315-326. https://doi.org/10.1080/01926180600969702

Bancroft, L., \& Silverman, J. (2002). The batterer as parent: Addressing the impact of domestic violence on family dynamics. Sage Publications.

Barlow, J., \& Schrader-MacMillan, A. (2009). Safeguarding children from emotional abuse - what works? (Research Brief DCSF-RBX-09-09). Department for Children, Schools and Families. Consulted 12. 7. 2021. at https://www. cscb-new.co.uk/downloads/reports_research/Safeguarding\%20Children\%20from\%20emotional\%20abuse.pdf

Becker-Weidman, A. (2006). Treatment for children with trauma-attachment disorders: Dyadic developmental psychotherapy. Child and Adolescent Social Work Journal, 23, 147-171. https://doi.org/10.1007/s10560-005-0039-0

Belsky, J. (1993). Etiology of child maltreatment: A developmental ecological analysis. Psychological Bulletin, 114(3), 413-434. https://doi.org/10.1037/0033-2909.114.3.413

Bentovim, A., Gray, J., \& Pizzey, S. (2018). Therapeutic interventions for looked after children, young people and theri caregivers. A modular approach: An introductory guide for practioners and managers. Child and Family Training.

Black D. W. (2000). The epidemiology and phenomenology of compulsive sexual behavior. CNS spectrums, 5(1), 26-72. https://doi.org/10.1017/s1092852900012645

Bol, C. (2008) Trauma focused therapy for the treatment of posttraumatic stress disorder in sexually abused children: A summary and evaluation of research. Graduate Journal of Counselling Psychology, 1, 147-158.

Bolger, K. E., \& Patterson, C. J. (2001). Developmental pathways from child maltreatment to peer rejection. Child Development, 72(2), 549-568. https://doi.org/10.1111/1467-8624.00296

Briere, J. (2002). Treating adult survivors of severe childhood abuse and neglect: Further development of an integrative model. In J. E. B. Myers, L. Berliner, J. Briere, C. T. Hendrix, C. Jenny, \& T. A. Reid (Eds.), The APSAC handbook on child maltreatment (pp. 175-203). Sage Publications, Inc.

Briere, J., \& Elliott, D. M. (1997). Psychological assessment of interpersonal victimization effects in adults and children. Psychotherapy: Theory, Research, Practice, Training, 34(4), 353-364. https://doi.org/10.1037/h0087848

Briggs-Gowan, M. J., Carter, A. S., \& Ford, J. D. (2012). Parsing the effects violence exposure in early childhood: modeling developmental pathways. Journal of Pediatric Psychology, 37(1), 11-22. https://doi.org/10.1093/jpepsy/ jsr063

Brunk, M., Henggeler, S. W., \& Whelan, J. P. (1987). Comparison of multisystemic therapy and parent training in the brief treatment of child abuse and neglect. Journal of Consulting and Clinical Psychology, 55(2), 171-178. https://doi.org/10.1037//0022-006x.55.2.171

Buljan Flander, G., \& Profaca, B. (2010). The responsibility and co-ordination of professionals in tackling child sexual abuse. In: Council of Europe Publishing (eds.), Protecting children from sexual violence - A comprehensive approach. Strasbourg Cedex: Council of Europe Publishing.153-163.

Cahn, N. (2006). Child witnessing of domestic violence. In N. E. Dowd, D. G. Singer, D. G. \& R. F. Wilson, (Eds.), Handbook of children, culture, and violence (pp. 3-20). Sage Publications. https://doi.org/10.4135/9781412976060.n1 
Carbonell, D. M., \& Parteleno-Barehmi, C. (1999). Psychodrama groups for girls coping with trauma. International Journal of Group Psychotherapy, 49(3), 285-306.

Cecil, C. A., Viding, E., Fearon, P., Glaser, D., \& McCrory, E. J. (2017). Disentangling the mental health impact of childhood abuse and neglect. Child Abuse \& Neglect, 63, 106-119. https://doi.org/10.1016/j.chiabu.2016.11.024

Chanmugam, A., \& Teasley, M. L. (2014). What should school social workers know about children exposed to adult intimate partner violence. Children \& Schools, 36, 195-198.

Child Welfare Information Gateway (2014). In-home services in child welfare. Department of Health and Human Services, Children's Bureau.

Chorpita, B. F., Daleiden, E. L., Park, A. L., Ward, A. M., Levy, M. C., Cromley, T., Chiu, A. W., Letamendi, A. M., Tsai, K. H., \& Krull, J. L. (2017). Child STEPS in California: A cluster randomized effectiveness trial comparing modular treatment with community implemented treatment for youth with anxiety, depression, conduct problems, or traumatic stress. Journal of Consulting and Clinical Psychology, 85, 13-25. https://doi.org/10.1037/ccp0000133

Chorpita, B. F., \& Weisz, J. R. (2009). Modular Approach to Children with Anxiety, Depression, Trauma and Conduct Match-ADTC. Practice Wise LCC.

Cicchetti, D., Hetzel, S., Rogosch, F. A., Handley, E. D., \& Toth, S. L. (2016). An investigation of child maltreatment and epigenetic mechanisms of mental and physical health risk. Development and psychopathology, 28(4pt2), 1305-1317. https://doi.org/10.1017/S0954579416000869

Cicchetti, D., Rogosch, F. A., Howe, M. L., \& Toth, S. L. (2010). The effects of maltreatment and neuroendocrine regulation on memory performance. Child development, 81(5), 1504-1519. https://doi.org/10.1111/j.14678624.2010.01488.x

Cicchetti, D., \& Valentino, K. (2006). An ecological-transactional perspective on child maltreatment: Failure of the average expectable environment and its influence on child development. In D. Cicchetti \& D. J. Cohen (Eds.), Developmental psychopathology: Risk, disorder, and adaptation (pp. 129-201). John Wiley \& Sons, Inc..

Cicchetti, D., \& Toth, S. L. (1998). The development of depression in children and adolescents. American Psychologist, 53(2), 221-241. https://doi.org/10.1037/0003-066X.53.2.221

Cicchetti, D., \& Lynch, M. (1993). Toward an ecological/transactional model of community violence and child maltreatment: Consequences for children's development. Psychiatry: Interpersonal and Biological Processes, 56(1), 96-118.

Cicchetti, D., \& Rizley, R. (1981). Developmental perspectives on the etiology, intergenerational transmission and sequelae of child maltreatment. New Directions for Child Development, 11, 32-59.

Cohen, J. A., Mannarino, A. P., Kliethermes, M., \& Murray, L. K. (2012). Trauma-focused CBT for youth with complex trauma. Child Abuse and Neglect, 35(6), 528-541. https://doi.org/10.1016/j.chiabu.2012.03.007

Cohen, J. A., Berliner, L., \& Mannarino, A. (2010). Trauma focused CBT for children with co-occurring trauma and behavior problems. Child Abuse \& Neglect, 34, 215-224. https://doi.org/10.1016/j.chiabu.2009.12.003

Cohen, J. A., Mannarino, A. P., \& Deblinger, E. (2006a). Treating Trauma and Traumatic Grief in Children and Adolescents. New York: The Guilford Press.

Cohen, J. A., Mannarino, A. P., Murray, L. K., \& Igelman, R. (2006b). Psychosocial interventions for maltreated and violence-exposed children. Journal of Social Issues, 62, 737-766. https://doi.org/10.1111/j.1540-4560.2006.00485.x

Cohen, J. A., Mannarino, A. P., \& Knudsen, K. (2005). Treating sexually abused children: 1-year follow-up of a randomized controlled trial. Child Abuse \& Neglect, 29, 135-145. https://doi.org/10.1016/j.chiabu.2004.12.005

Cook, J. M., Schnurr, P. P., \& Foa, E. B. (2004). Bridging the gap between posttraumatic stress disorder research and clinical practice: The example of exposure therapy. Psychotherapy: Theory, Research, Practice, Training, 41(4), 374-387. https://doi.org/10.1037/0033-3204.41.4.374 
Cook, A., Blaustein, M., Spinazzola, J., \& van der Kolk, B. (2003). Complex trauma in children and adolescents. Los Angeles, CA and Durham, NC: The National Child Traumatic Stress Network . Retrieved from http://www. nctsnet.org/nctsn_assets/pdfs/edu_materials/ComplexTrauma_All.pdf

Corcoran, J. (2000). Family interventions with child physical abuse and neglect: A critical review. Children and Youth Services Review, 22, 563-591. https://doi.org/10.1016/S0190-7409(00)00103-1

Courtois, C. A., \& Ford, J. D. (Eds.). (2009). Treating complex traumatic stress disorders: An evidence-based guide. The Guilford Press.

Damashek, A. L., \& Chaffin, M. J. (2012). Handbook of evidence-based practice in clinical psychology. In P. Sturmey, \& M. Hersen (Eds.), Child Abuse and Neglect (pp. 647-678). New York: John Wiley \& Sons, Inc. https://doi. org/10.1002/9781118156391.ebcp001028

de Arellano, M. A. R., Lyman, D. R., Jobe-Shields, L., George, P., Dougherty, R. H., Daniels, A. S., Ghose, S. S., Huang, L., \& Delphin-Rittmon, M. E. (2014). Trauma-focused cognitive-behavioral therapy for children and adolescents: assessing the evidence. Psychiatric services (Washington, D.C.), 65(5), 591-602. https://doi.org/10.1176/appi. ps. 201300255

De Bellis, M. D., Woolley, D. P., \& Hooper, S. R. (2013). Neuropsychological findings in pediatric maltreatment: relationship of PTSD, dissociative symptoms, and abuse/neglect indices to neurocognitive outcomes. Child maltreatment, 18(3), 171-183. https://doi.org/10.1177/1077559513497420

Deblinger, E., \& Runyon, M. K. (2005). Understanding and Treating Feelings of Shame in Children Who Have Experienced Maltreatment. Child Maltreatment, 10(4), 364-376. https://doi.org/10.1177/1077559505279306

Diamond, G., Russon, J., \& Levy, S. (2016). Attachment-Based Family Therapy: A Review of the Empirical Support. Family process, 55(3), 595-610. https://doi.org/10.1111/famp.12241

Diamond, G. S., Diamond, G. M., \& Levy, S. A. (2013). Attachment-based family therapy for depressed adolescents. Washington, D. C: American Psychological Association.

de Arellano, M. A., Lyman, D. R., Jobe-Shields, L., George, P., Dougherty, R. H., Daniels, A. S., Ghose, S. S., Huang, L., \& Delphin-Rittmon, M. E. (2014). Trauma-focused cognitive-behavioral therapy for children and adolescents: assessing the evidence. Psychiatric Services (Washington, D.C.), 65(5), 591-602. https://doi.org/10.1176/appi. ps. 201300255

de Graff, I., Speetjens, P., Smit, F., de Wolff, M., \& Tavecchio, L. (2008). Effectiveness of the Triple P Positive Parenting Program on parenting: A meta-analysis. Behavior Modification, 32(5), 714-735. https://doi. org $/ 10.1177 / 0145445508317134$

Devaney, J. (2015). Research review: The impact of domestic violence on children. Irish Probation Journal, 12, 79-94.

Dodaj, A., \& Sesar, K. (2020). Conequences of child abuse and neglect. Central European Journal of Paediatry, 16(2), 168-181. https://doi.org/10.5457/p2005-114.71

Dodaj, A., Krajina, M., Sesar, K., \& Šimić, N. (2017). The effects of maltreatment in childhood on working memory capacity in adulthood. Europe's Journal of Psychology, 13(4), 618-632. https://doi.org/10.5964/ejop.v13i4.1373.

Donohue, B., Romero, V., \& Hill, H. H. (2006). Treatment of co-occurring child maltreatment and substance abuse. Aggression and Violent Behavior, 11(6), 626-640. https://doi.org/10.1016/j.avb.2005.08.007

Feather, J. S., Ronan, K. R. (2009). Trauma-focused CBT with maltreated children: A clinic-based evaluation of a new treatment manual. Australian Psychologist, 44, 174-194. https://doi.org/10.1080/00050060903147083

Foy, D. W., Eriksson, C. B., \& Trice, G. A. (2001). Introduction to group interventions for trauma survivors. Group Dynamics: Theory, Research, and Practice, 5(4), 246-251. https://doi.org/10.1037/1089-2699.5.4.246

Grasso, D. J., Joselow, B., Marquez, Y., \& Webb, C. (2011). Trauma-focused cognitive behavioural therapy of a child with posttraumatic stress disorder. Psychotherapy, 48, 188-197. https://doi.org/10.1037/a0023133 
Heim, C., Bradley, B., Mletzko, T. C., Deveau, T. C., Musselman, D. L., Nemeroff, C. B., Ressler, K. J., \& Binder, E. B. (2009). Effect of Childhood Trauma on Adult Depression and Neuroendocrine Function: Sex-Specific Moderation by CRH Receptor 1 Gene. Frontiers in Behavioral Neuroscience, 3, 41. https://doi.org/10.3389/neuro.08.041.2009

Heiman, M. L., \& Ettin, M. F. (2001). Harnessing the power of the group for latency-aged sexual abuse victims. International Journal of Group Psychotherapy, 51, 265-282.

Herman, J. L. (1992). Trauma and recovery. Basic Books/Hachette Book Group.

Hetzel-Riggin, M. D., Brausch, A. M., \& Montgomery, B. S. (2007). A meta-analytic investigation of therapy modality outcomes for sexually abused children and adolescents: An exploratory study. Child Abuse \& Neglect, 31(2), 125-141. https://doi.org/10.1016/j.chiabu.2006.10.007

Huemer, J., Erhart, F., \& Steiner, H. (2010). Posttraumatic stress disorder in children and adolescents: A Review of psychopharmacological treatment. Child Psychiatry \& Human Development, 41, 624-640. https://doi.org/10.1007/ s10578-010-0192-3

Hofer, M. A. (2006). Psychobiological Roots of Early Attachment. Current Directions in Psychological Science, 15(2), 84-88. https://doi.org/10.1111/j.0963-7214.2006.00412.x

IOM (Institute of Medicine), \& NRC (National Research Council). (2014). New directions in child abuse and neglect research. National Academies Press.

Jaberghaderi, N., Greenwald, R., Rubin, A., Zand, S. O., \& Dolatabadi, S. (2004). A comparison of CBT and EMDR for sexually-abused Iranian girls. Clinical Psychology and Psychotherapy, 11, 358-368. https://doi.org/10.1002/cpp.395

Jaycox, L. (2004). Cognitive Behavioral Intervention for Trauma in Schools (CBITS). Longmont, CO: SoprisWest.

Kanel, K. (2015). A guide to crisis intervention (5th ed.). Stanford, CT: Cengage Learning.

Kataoka, S., Jaycox, L. H., Wong, M., Nadeem, E., Langley, A., Tang, L., \& Stein, B. D. (2011). Effects on school outcomes in low-income minority youth: preliminary findings from a community-partnered study of a schoolbased trauma intervention. Ethnicity \& Disease, 21(3 Suppl 1), S1-77.

Knudsen, E. I. (2004). Sensitive Periods in the Development of the Brain and Behavior. Journal of Cognitive Neuroscience, 16(8), 1412-1425. https://doi.org/10.1162/0898929042304796

Krauthamer Ewing, E. S., Levy, S. A., Boamah-Wiafe, L., Kobak, R., \& Diamond, G. (2016). Attachment-Based Family Therapy With a 13-Year-Old Girl Presenting With High Risk for Suicide. Journal of Marital and Family Therapy, 42(1), 91-105. https://doi.org/10.1111/jmft.12102

Lauterbach, D., \& Armour, C. (2016). Symptom Trajectories Among Child Survivors of Maltreatment: Findings from the Longitudinal Studies of Child Abuse and Neglect (LONGSCAN). Journal of Abnormal Child Psychology, 44(2), 369-379. https://doi.org/10.1007/s10802-015-9998-6

Leeson, F. J., \& Nixon, R. D. (2011). The role of children's appraisals on adjustment following psychological maltreatment: a pilot study. Journal of Abnormal Child Psychology, 39(5), 759-771. https://doi.org/10.1007/ s10802-011-9507-5

Lev-Wiesel, R. (2015). Childhood Sexual Abuse: From Conceptualization to Treatment. Journal of Trauma and Treatment, 4, 4. 1000259. http://dx.doi.org/10.4172/2167-1222.1000259

Lieberman, A. F., \& Knorr, K. (2007). The impact of trauma: A development framework for infancy and early childhood. Psychiatric Annals, 37(6), 416-422. https://doi.org/10.3928/00485713-20070601-05

Lindon, J., \& Nourse, C. A. (1994). A multi-dimensional model of group work for adolescent girls who have been sexually abused. Child Abuse \& Neglect, 18(4), 341-348. https://doi.org/10.1016/0145-2134(94)90036-1

Lomonaco, S., Scheidlinger, S., \& Aronson, S. (2000). Five decades of children's group treatment-An overview. Journal of Child and Adolescent Group Therapy, 10, 77-96. 
Lynch, M., \& Cicchetti, D. (1998). An ecological-transactional analysis of children and contexts: The longitudinal interplay among child maltreatment, community violence, and children's symptomatology. Development and Psychopathology, 10(2), 235-257. https://doi.org/10.1017/S095457949800159X

Mather, J., Lager, P. B., \& Harris, N. J. (2007). Child welfare: Policies and best practices. Brooks/Cole.

Mazzucchelli, T. G., \& Sanders, M. R. (2010). Facilitating practitioner flexibility within an empirically supported intervention: Lessons from a system of parenting support. Clinical Psychology: Science and Practice, 17(3), 238252. https://doi.org/10.1111/j.1468-2850.2010.01215.x

May, J. C. (2005). Family attachment narrative therapy: Healing the experience of early childhood maltreatment. Journal of Marital and Family Therapy, 31, 221-237. https://doi.org/10.1111/j.1752-0606.2005.tb01565.x

McConnell, N., Barnard, M., Holdsworth, T., \& Taylor, J. (2014). Caring Dads-Safer Children: An interim evaluation report. National Society for the Prevention of Cruelty to Children.

McMahon, M., Devaney, J., \& Lazenbatt, A. (2009). The role of theory in promoting social work values and its potential effect on outcomes in work with domestically violent men. Irish Probation Journal, 6, 151-170.

McNeil, C. B., \& Hembree-Kigin, T. L. (2010). Parent-child interaction therapy. Springer. https://doi.org/10.1007/978$0-387-88639-8$

Meezan, W., \& O'Keefe, M. (1998). Evaluating the effectiveness of multifamily group therapy in child abuse and neglect. Research on Social Work Practice, 8(3), 330-353. https://doi.org/10.1177/104973159800800306

Mersky, J. P., \& Reynolds, A. J. (2007). Predictors of early childbearing: Evidence from the Chicago longitudinal study. Children and Youth Services Review, 29(1), 35-52. https://doi.org/10.1016/j.childyouth.2006.03.009

Misurell, J., Springer, C., Acosta, L., Liotta, L., \& Kranzler, A. (2014). Game based cognitive-behavioral therapy individual model (GB-CBT-IM) for child sexual abuse: A preliminary outcome study. Psychological Trauma: Theory, Research, Practice, and Policy, 6, 250-258. https://doi.org/10.1037/a0033411

Moher, D., Liberati, A., Tetzlaff, J., \& Altman, D. G. (2009). Preferred reporting items for systematic reviews and metaanalyses: The PRISMA statement. PLoS Medicine, 6(7), e1000097 https://doi.org/10.1371/journal.pmed.1000097

Morsette, A., Swaney, G., Stolle, D., Schuldberg, D., van den Pol, R., \& Young, M. (2009). Cognitive Behavioral Intervention for Trauma in Schools (CBITS): school-based treatment on a rural American Indian reservation. Journal of Behavior Therapy and Experimental Psychiatry, 40(1), 169-178. https://doi.org/10.1016/j.jbtep.2008.07.006

Nemeroff, C. B. (2004). Neurobiological consequences of childhood trauma. The Journal of Clinical Psychiatry, 65(Suppl1), 18-28.

Perlman, S. B., Kalish, C., \& Pollak, S. D. (2008). The role of maltreatment experience in children's understanding of the antecedents of emotion. Cognition and Emotion, 22(4), 651-670.

Profaca, B. (2016). Traumatizacija djece i mladi. Ljetopis socijalnog rada, 23(3), 345-361

Profaca, B., \& Arambašić, L. (2009). Traumatski događaji i trauma kod djece i mladih. Klinička psihologija, 2(1-2), 53-73.

Pynoos, R. S., Steinberg, A. M., \& Wraith, R. (1995). A developmental model of childhood traumatic stress. In D. Cicchetti \& D. Cohen (Eds.), Manual of developmental psychopathology: Vol. 2. Risk, disorder, and adaptation (pp. 72-95). New York: Wiley.

Pynoos, R. S., \& Nader, K. (1990). Children's exposure to violence and traumatic death. Psychiatric Annals, 20(6), 334-344. https://doi.org/10.3928/0048-5713-19900601-11

Royse, D. (2015). Emotional abuse of children: Essential information. Routledge. https://doi.org/10.4324/9781315736402

Runyon, M. K., Deblinger, E., \& Schroeder, C. M. (2009). Pilot evaluation of outcomes of combined parent-child cognitive-behavioral group therapy for families at-risk for child physical abuse. Cognitive and Behavioral Practice, 16(1), 101-118. https://doi.org/10.1016/j.cbpra.2008.09.006 
Sackett, D. L., Straus, S. E., Richardson, W. S., Rosenberd, W., \& Hayns, R. B. (2000). Evidenced-based medicine: How to practice and teach EMB. Churchill Livingstone.

Sanders, M. R., Markie-Dadds, C., Tully, L. A., \& Bor, W. (2000). The Triple P-Positive Parent Program: A comparison of enhances, standard and behavioral family intervention for parents of children with early onset conduct problems. Journal of Consulting and Clinical Psychology, 68(4), 624-640. https://doi.org/10.1037/0022-006X.68.4.624

Saywitz, K. J., Mannarino, A. P., Berliner, L., \& Cohen, J. A. (2000). Treatment for sexually abused children and adolescents. American Psychologist, 55(9), 1040-1049. https://doi.org/10.1037/0003-066X.55.9.1040

Scheeringa, M. S., Weems, C. F., Cohen, J. A., Amaya-Jackson, L., \& Guthrie, D. (2011). Trauma-focused cognitivebehavioral therapy for posttraumatic stress disorder in three through six-year-old children: A randomized clinical trial. Journal of Child Psychology and Psychiatry, 52, 853-860. https://doi.org/10.1111/j.1469-7610.2010.02354.x

Schofield, T. J., Lee, R. D., \& Merrick, M. T. (2013). Safe, stable, nurturing relationships as a moderator of intergenerational continuity of child maltreatment: a meta-analysis. The Journal of adolescent health: official publication of the Society for Adolescent Medicine, 53(4 Suppl), S32-S38. https://doi.org/10.1016/j. jadohealth.2013.05.004

Scott, D. (2014). Understanding child neglect. Child Family Community Australia, Australian Institute of Family Studies. Consulted 20. 8. 2020. at https://aifs.gov.au/cfca/publications/understanding-child-neglect

Scott, T.A., Burlingame, G., Starling, M., Porter, C., \& Lilly, J.P. (2003). Effects of individual client-centered play therapy on sexually abused children's mood, self-concept, and social competence. International Journal of Play Therapy, 12, 7-30. https://doi.org/10.1037/h0088869

Sesar, K., Šimić, N., \& Barišić, M. (2010). Multy-type Childhood Abuse, Strategies of Coping, and Psychological Adaptations in Young Adults. Croatian Medical Journal, 51(5), 406-416.

Sesar, K., Živčić - Bećirević, I., \& Sesar, D. (2008). Multitype Maltreatment in Childhood and Psychological Adjustment in Adolescence: Questionnaire Study. Croatian Medical Journal, 49, 2432-58.

Shapiro F. (2014). The role of eye movement desensitization and reprocessing (EMDR) therapy in medicine: addressing the psychological and physical symptoms stemming from adverse life experiences. The Permanente journal, 18(1), 71-77. https://doi.org/10.7812/TPP/13-098

Shapiro F. (2012). EMDR therapy training manual. Watsonville, CA: EMDR Institute.

Shapiro, F., Kaslow, F. W., \& Maxfield, L. (2007). Handbook of EMDR and Family Therapy Processes. John Wiley \& Sons. https://doi.org/10.1002/9781118269985

Sinanan, A. N. (2015). Trauma and Treatment of Child Sexual Abuse. Journal of Trauma \& Treatment, s4, 024. https:// doi.org/10.4172/2167-1222.S4-024

Stubenhort, K., Cohen, M. M., \& Trybalski, V. (2010). The effectiveness of an attachment-focused treatment model in a therapeutic preschool for abused children. Clinical Social Work Journal, 38, 51-60. https://doi.org/10.1007/ s10615-007-0107-3

Swenson, C. C., Schaeffer, C. M., Henggeler, S. W., Faldowski, R., \& Mayhew, A. M. (2010). Multisystemic therapy for child abuse and neglect: A randomized effectiveness trial. Journal of Family Psychology, 24(4), 497-507. https://doi.org/10.1037/a0020324

Swenson, C. C., \& Schaeffer, C. M. (2018). A Multisystemic Approach to the Prevention and Treatment of Child Abuse and Neglect. International Journal on Child Maltreatment: Research, Policy and Practise, 1(1), 97-120. https://doi.org/10.1007/s42448-018-0002-2

Tavkar, P., \& Hansen, D. J. (2011). Interventions for families victimized by child sexual abuse: Clinical issues and approaches for child advocacy center-based services. Faculty Publications, Department of Psychology.

Teicher, M. H., Anderson, C. M., \& Polcari, A. (2012). Childhood maltreatment is associated with reduced volume in the hippocampal subfields CA3, dentate gyrus, and subiculum. Proceedings of the National Academy of Sciences of the United States of America, 109(9), E563-E572. https://doi.org/10.1073/pnas.1115396109 
Trocmé, N., Fallon, B., Sinha, V., Wert, M. V, Kozlowski, A., \& MacLaurin, B. (2013). Differentiating between child protection and family support in the Canadian child welfare system's response to intimate partner violence, corporal punishment and child neglect. International Journal of Psychology, 48(2), 128-140. https://doi.org/10. 1080/00207594.2013.765571

Trowell, J., Kolvin, I., Weeramanthri, T., Sadowski, H., Berelowitz, M., Glasser, D., \& Leitch, I. (2002). Psychotherapy for sexually abused girls: Psychopathological outcome findings and patterns of change. British Journal of Psychiatry, 180, 234- 247. https://doi.org/10.1192/bjp.180.3.234

Urquiza, A., \& Timmer, S. (2014). Parent-child interaction therapy for maltreated children. In S. Timmer \& A. Urquiza (Eds.), Evidence-based approaches for the treatment of maltreated children: Considering core components and treatment effectiveness (pp. 123-144). Springer Science + Business Media. https://doi.org/10.1007/978-94-0077404-9_8

Zindler, P., Hogan, A., \& Graham, M. (2010). Addressing the unique and trauma-related needs of young children. Consulted 20. 8. 2020. at https://www.yumpu.com/en/ document/view/11315021/addressing-the-unique-andtraumarelated-needs-of-young-children

Wanlass, J., Moreno, J. K., \& Thomson, H. M. (2006). Group Therapy for Abused and Neglected Youth: Therapeutic and Child Advocacy Challenges. Journal for Specialists in Group Work, 31(4), 311-326. https://doi. org/10.1080/01933920600918808

Westbury, E., \& Tutty, L. M. (1999). The efficacy of group treatment for survivors of childhood abuse. Child Abuse \& Neglect, 23(1), 31-44. https://doi.org/10.1016/S0145-2134(98)00109-4

Yalom, I. D., \& Leszcz, M. (2005). Theory and practice of group psychotherapy. Basic Books. 